\title{
When HIV Immunodeficiency and Heterochromia Confuse the Issue: Recurrent Zoster Uveitis Mistaken for Fuchs' Uveitis
}

\author{
Ioannis Papasavvas, MD; Bruno Jeannin, COP; Carle Pierre Herbort, MD, PD
}

Retinal and Inflammatory Eye Diseases, Centre for Ophthalmic Specialized Care (COS), Clinic Montchoisi Teaching Centre, Lausanne, Switzerland

\section{Abstract}

Purpose: We report a case with iris heterochromia misdiagnosed as Fuchs' uveitis which finally turned out to be a unilateral zoster uveitis in an HIV-positive patient.

Case Report: A 45-year old patient was seen for a recurrent right anterior uveitis treated with prednisolone $1 \%$ drops BID. The iris of the right eye was hypochromic and atrophic and several small granulomatous keratic precipitates (KPs) were present. After discontinuation of corticosteroid drops, severe uveitis developed with mutton-fat KPs, and laser flare photometry (LFP) increased from 20 to $50.3 \mathrm{ph} / \mathrm{ms}$. He had presented with right zoster ophthalmicus two years earlier and HIV-serology revealed to be positive.

Conclusion: Iris heterochromia is not a good disease-defining criterion for Fuch's uveitis even when typical KPs are present and can lead to misdiagnosis. More reliable criteria including stellate KPs, low LFP values, absence of synechiae, vitreitis, and disc hyperfluorescence, all absent in this case, should be sought to confirm or exclude the diagnosis.

Keywords: Herpes Zoster Uveitis; Heterochromia; HIV

J Ophthalmic Vis Res 2021; 16 (2): 295-299

\section{INTRODUCTION}

Fuchs' uveitis (FU) is often underdiagnosed because too much importance is given to iris heterochromia at the expense of other more disease-defining clinical signs. The disease was described by Ernst Fuchs at the beginning of the last century in Vienna, Austria, inhabited by

Correspondence to:

Carl P. Herbort Jr, MD, PD. Centre for Ophthalmic Specialised Care (COS), Montchoisi Teaching Centre, Rue Charles-Monnard 6, Lausanne, Switzerland.

Email: cph@herbortuveitis.ch

Received: 21-06-2020 Accepted: 21-01-2021

\section{Access this article online}

Website: https://knepublishing.com/index.php/JOVR

DOI: 10.18502/jovr.v16i2.9094 a Caucasian population. ${ }^{[1,2]}$ Iris heterochromia had a prominent part in the definition of the disease in his publications ${ }^{[1]}$ and his textbook, which was translated into more than 10 languages including countries with all brown iris populations. In these countries such as Japan ${ }^{[3]}$ and many others, FU was underdiagnosed because clinicians were (1) looking in vain for heterochromia that does not exist in brown irises and (2) ignored the clinical sign of vitreitis present in close to $100 \%$ of cases. ${ }^{[4]}$ Therefore, strong and universal

This is an open access journal, and articles are distributed under the terms of the Creative Commons Attribution-NonCommercial-ShareAlike 4.0 License, which allows others to remix, tweak, and build upon the work non-commercially, as long as appropriate credit is given and the new creations are licensed under the identical terms. 
disease-defining signs have to be used to confirm or exclude FU. These criteria, all present in $>90 \%$ of non-operated cases, include vitritis, ${ }^{[4]}$ small stellate keratic precipitates (KPs), low aqueous flare values measured by laser flare photometry (LFP, $\leq 20 \mathrm{ph} / \mathrm{ms}),{ }^{[5]}$ absence of posterior synechiae, difference of texture of irises between the two eyes, absence of cystoid macular oedema, and hyperfluorescent disc on fluorescein angiography $(F A){ }^{[6]}$ Here, we present a case where iris heterochromia led to falsely diagnosed FU in a case of recurrent zoster uveitis in an immunocompromised patient.

\section{CASE REPORT}

A 45-year old teacher was referred to our uveitis clinic by his treating eye doctor for a recurrent right granulomatous uveitis. History revealed that he had gone through right herpes zoster ophthalmicus (HZ.O) two years prior.

At presentation, the patient was under the treatment of $1 \%$ prednisolone acetate eye drop, twice daily. Uncorrected visual acuity ODS was 1.0 on the Snellen chart.

On the right corneal endothelium, there were rare small randomly distributed stellate KPs compatible with FU [Figure 1]. The anterior chamber was uninflamed on slit-lamp examination but LFP measured a sub-clinical inflammation of $20.2 \mathrm{ph} / \mathrm{ms}$ (normal $=3-6 \mathrm{ph} / \mathrm{ms}$ ). Intraocular pressure was $12 \mathrm{mmHg}$ OD and $14 \mathrm{mmHg}$ OS. An iris heterochromia was noted with a lighter iris on the right and an altered hyalinized iris surface [Figure 2]. There was no sectorial iris atrophy. There were rare cells in the anterior vitreous OD. Fundus examination as well as retinal and choroidal optical tomography (OCT) were normal. We made the diagnosis of FU based on typical KPs and heterochromia and stopped the corticosteroid drops. FA performed the following day did not show the disc hyperfluorescence usually seen in FU [Figure 3] nor the limited peripheral vascular leakage often present in FU. Ten days later, the patient returned with a severe granulomatous uveitis with numerous mutton-fat KPs [Figure 4] and increase of LFP values to $51.4 \mathrm{ph} / \mathrm{ms}$ associated with posterior synechiae [Figure 4]. The diagnosis was revised to recurrent zoster uveitis and the patient was treated with valacyclovir $1000 \mathrm{mg}$ TID and
$1 \%$ prednisolone acetate drops $5 \times$ per day. The uveitis responded well to treatment with resolution of the mutton-fat KPs and reduction of LFP values to $20.7 \mathrm{ph} / \mathrm{ms}$. However, at each tapering attempt, the uveitis recurred. As we suspected an immune deficiency to varicellazoster virus or a more general immunodepression, we asked the patient to give us his consent to search for HIV infection. HIV serology was positive, and the CD4 lymphocyte count was reduced to 332 cells $/ \mathrm{mm} 3$. After the two attempts to taper the treatment, we decided to leave the patient under combined systemic antiviral treatment and corticosteroid drops and to wait until the CD4 count would be back to normal after the initiation of antiretroviral therapy.

\section{DISCUSSION}

Iris heterochromia is still too strongly associated with FU while better disease-defining criteria have been put forward. ${ }^{[6,7]}$ Outside FU, viralrelated iris heterochromia has been described in association with cytomegalovirus ${ }^{[8]}$ and with Ebola virus. ${ }^{[9]}$ In a large series of viral anterior uveitis cases with etiologic agents proven by aqueous $\mathrm{PCR}$, iris heterochromia was never detected in varicella-zoster uveitis. ${ }^{[10]}$ Although a thorough literature search remained negative, it is not impossible "a priori" that zoster uveitis can produce heterochromia, which was the case in our patient.

The differential diagnosis of FU and herpetic anterior uveitis can be easier when large, mutton fat-like KP's are present, which can exclude FU. In the early stages of herpetic anterior uveitis, mutton-fat KP's can very rarely be absent, confusing the ophthalmologist. They can also be absent after a period of local corticosteroid treatment, as it happened in our case, which can lead to misdiagnosis. Discontinuing the corticosteroid drops and re-examining our patient after 10 days revealed abundant mutton-fat KPs, increase of flare and posterior synechiae, features incompatible with FU.

Once FU was excluded and after two failed attempts to taper antiviral and corticosteroid treatment, we decided to search for an immune deficiency specifically to varicella-zoster virus (VZV) or a more global immunodeficiency. It is known that herpes zoster in patients under the age 


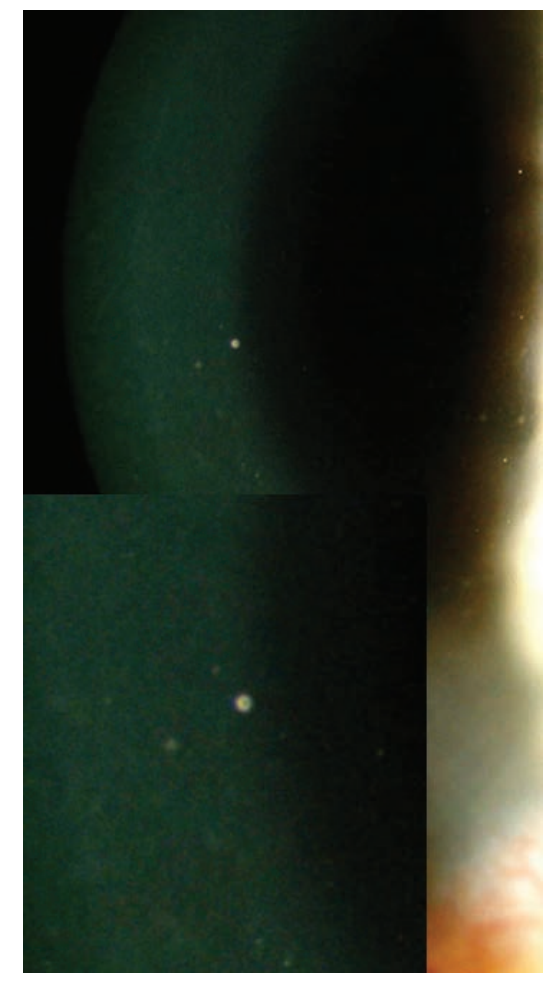

Figure 1. Sparse micro-granulomatous KPs, seen in magnification (insert) at presentation under the treatment of $1 \%$ prednisolone drops BID.

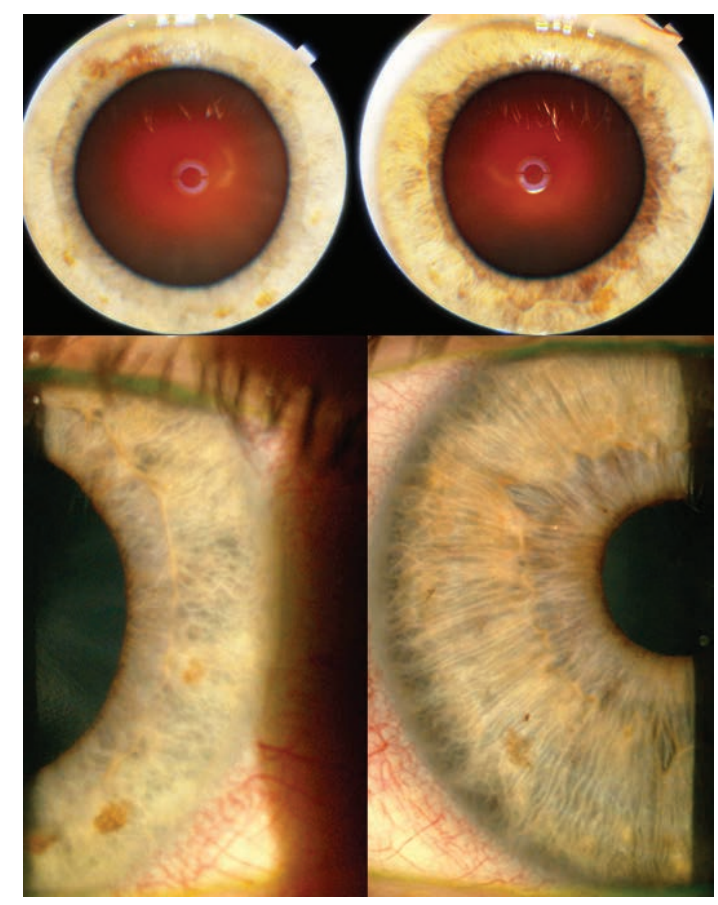

Figure 2. Heterochromia with a lighter-colored iris on the right (top). Bottom two pictures show a right discolored iris with an altered hyalinized iris texture (left picture). 

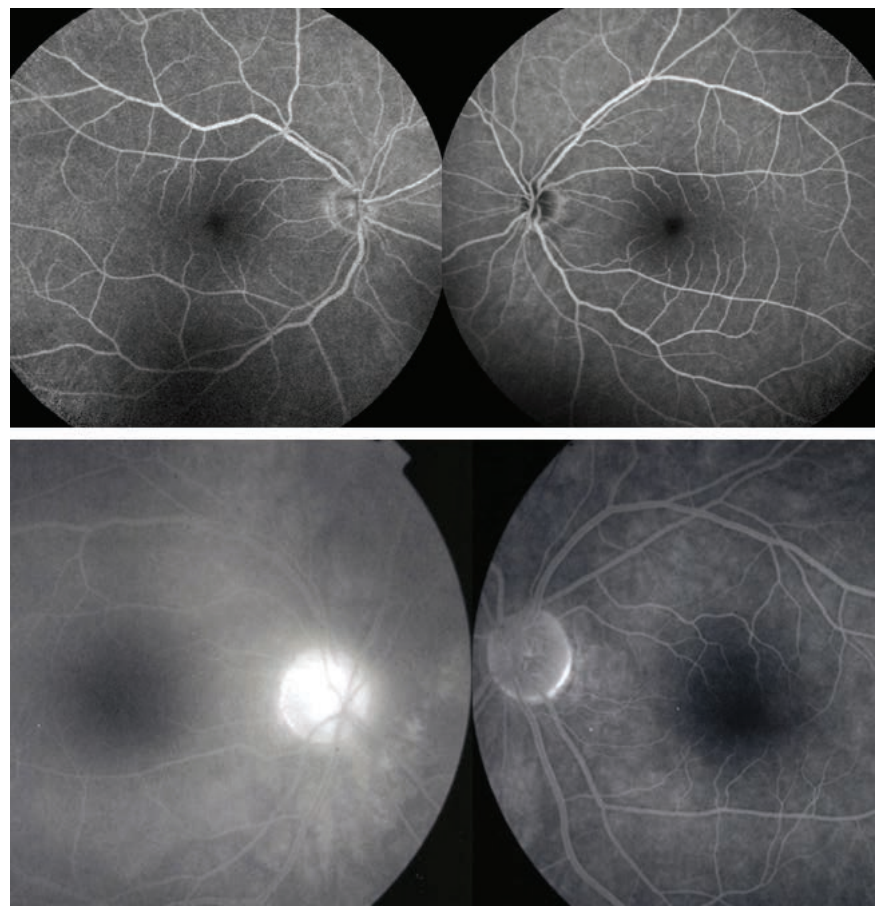

Figure 3. Absence of disc hyperfluorescence in the right affected eye on FA in the presented case (top angiographic frames). In comparison, bottom two frames show the typical disc hyperfluorescence seen in Fuchs' uveitis.

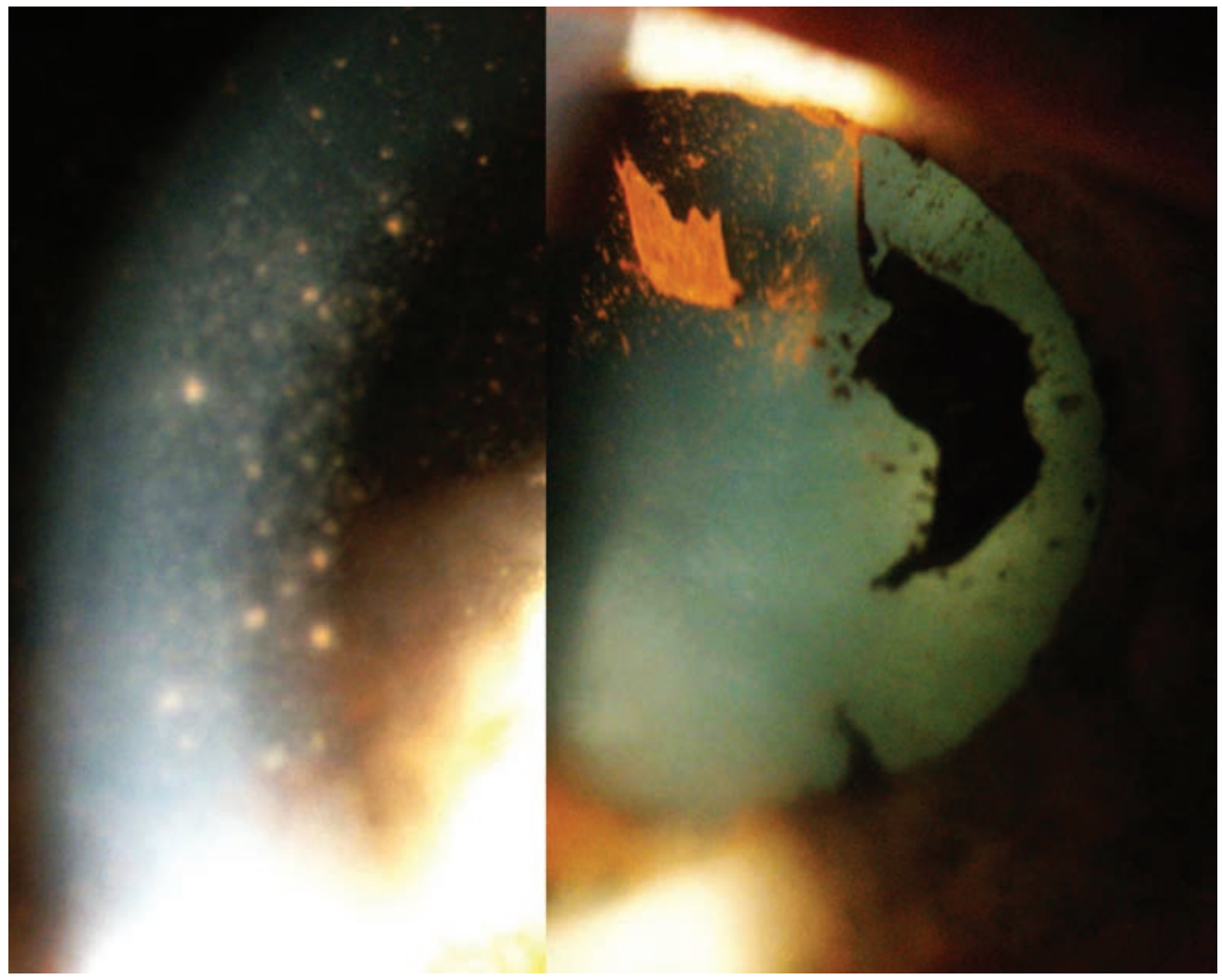

Figure 4. Massive mutton-fat KPs deposition on the endothelium in the right eye (left picture) after discontinuation of corticosteroid drops and posterior ruptured synechiae (right picture), incompatible with Fuchs' uveitis. 
of 50 is associated with HIV infection. In patients with a CD4 count from 200 to 349 cells $/ \mathrm{mm}^{3}$ which was the case for our patient, herpes zoster is listed as the third most frequent clinical condition (12\%) of missed opportunity for earlier diagnosis of HIV infection. ${ }^{[11]}$ Another trial showed that herpes zoster was a clinical event in late presenters with HIV infection indicating missed opportunities for earlier diagnosis in $19.8 \%$ of the cases. ${ }^{[12]}$

On the other hand, it was shown in a series of 89/581 (14.3\%) HIV-positive uveitis patients that the first cause of anterior uveitis was due to VZV amounting to $43 \%{ }^{[13]}$

VZV was shown to persist for much longer in tissues of HIV-positive patients and even that there was a rebound inflammation when anti-retroviral treatment was started. ${ }^{[14,15]}$ Therefore, we left the patient under dual systemic antiviral and topical corticosteroid therapy after introduction of antiretroviral therapy and CD4 count recovery.

The ophthalmologist, in presence of VZV pathology in patients under the age of 50 , should function as a whistle blower in order not to miss an early diagnostic opportunity for HIV infection.

\section{Financial Support and Sponsorship}

Nil.

\section{Conflicts of Interest}

None.

\section{REFERENCES}

1. Fuchs E. Ueber komplikationen der heterochromie. $Z$ Augenheilkd 1906;15:191-212.

2. Herbort CP, Khairallah M. Editorial: fuchs uveitis: from Imperial Vienna to global appraisal. Int Ophthalmol 2010;30:449-452
3. Higuchi M, Ohno S, Matsuda H. Clinical characteristics of Fuchs' heterochromic iridocyclitis. Rinsho Ganka 1982;36:1275-1280.

4. Bouchenaki N, Herbort CP. Fuchs' uveitis: failure to associate vitritis and disc hyperfluorescence with the disease is the major factor for misdiagnosis and diagnostic delay. Middle East Afr J Ophthalmol 2009;16:239244.

5. Guex-Crosier Y, Pittet N, Herbort CP. Evaluation of laser flare photometry in the appraisal and management of intraocular inflammation in uveitis. Ophthalmology 1994;101:728-735.

6. Bouchenaki N, Herbort CP. Fluorescein angiographic findings and clinical features in Fuchs' uveitis. Int Ophthalmol 2010;30:511-519.

7. Tugal-Tutkun I, Güney-Tefekli E, Kamaci-Duman F, Corum I. A cross-sectional and longitudinal study of Fuchs' uveitis syndrome in Turkish patients. Am J Ophthalmol 2009;148:510-515.

8. Hedayatfar A, Chee SP. Posner Schlossman syndrome associated with cytomegalovirus infection: a case series from a non-endemic area. Int Ophthalmol 2014;34:11231129.

9. Shantha JG, Crozier I, Varkey JD, et al. Long-term management of panuveitis and iris heterochromia in an Ebola survivor. Ophthalmology 2016;123:2626-2628.

10. Wensing B, Relvas LM, Caspers LE, Vidovic Valentincic N, Stunf S, Groot-Mijnes JDF, et al. Comparison of Rubella virus and Herpes virus-associated anterior uveitis. Ophthalmology 2011;118:1905-1910.

11. Nanditha NGA, St-Jean M, Tafessu H, Guillemi SA, Hull MW, Lu M, et al. Missed opportunities for earlier diagnosis of HIV in British Columbia, Canada: e retrospective cohort study. PLoS ONE 2019;14:e0214012.

12. Van den Bogaart L, Ranzani A, Oreni L, Giacomelli A, Corbellino M, Rusconi S, et al. Overlooked cases of HIV infection: an Italian tale of missed diagnostic opportunities. Eur J Intern Med 2020;73:30-35.

13. Mwanza JC, Kayembe DL. Uveitis in HIV-infected patients. Eur J Opthalmol 2001;11:53-56.

14. Biswas J, Sudharshan S. Anterior segment manifestations of human immunodeficiency virus/acquired immune deficiency syndrome. Indian J Ophthalmol 2008;56:363375.

15. Martinez E, Gatell J, Moran Y, Aznar E, Buira E, Guelar A, et al. High incidence of herpes zoster in patients with AIDS soon after therapy with protease inhibitors. Clin Infect Dis 1998;27:1510-1513. 